\title{
Angelo Mosso: Transduction and Measurement of Physiological Signals
}

\author{
Mara Fausone, Marco Galloni \\ ASTUT, Archivio Scientifico e Tecnologico dell'Università di Torino, Sistema Museale di Ateneo, C.so Massimo d'Azeglio, 5210126 Torino, \\ Italy
}

\begin{abstract}
Professor Angelo Mosso (1846-1910) was an Italian physiologist who worked in the University of Turin in the second half of nineteenth century. His researches were devoted to record and measure vital and mental processes. He invented many instruments and the signals were recorded on blackened paper on kymograph. In his work Mosso had the important help of the technician Luigi Corino, whose skill allowed to obtain very precise and functional instruments. In the storage rooms of ASTUT we preserve many of these instruments together with original documents, pictures.
\end{abstract}

\section{Section: TECHNICAL NOTE}

Keywords: Angelo Mosso; physiology; kymograph; measures of physiological processes

Citation: Mara Fausone, Marco Galloni, Angelo Mosso: Transduction and Measurement of Physiological Signals, Acta IMEKO, vol. 7, no. 2, article 19, June 2018, identifier: IMEKO-ACTA-07 (2018)-02-19

Section Editor: Lorenzo Ciani, University of Florence, Italy

Received February 11, 2018; In final form May 21, 2018; Published June 2018

Copyright: () 2018 IMEKO. This is an open-access article distributed under the terms of the Creative Commons Attribution 3.0 License, which permits unrestricted use, distribution, and reproduction in any medium, provided the original author and source are credited

Corresponding author: Mara Fausone, e-mail: mara.fausone@unito.it

\section{INTRODUCTION}

The Archivio Scientifico e Tecnologico dell'Università di Torino (ASTUT) was founded in 1992 when some researchers realized that it was necessary to create an institution devoted to the preservation of the heritage of scientific instruments, witnessing the history of science of our University.

In the University of Turin, six centuries old, there are important historical archives that preserve a large quantity of books and documents, but nobody had thought of collecting the material heritage.

In 1991, in the ancient rooms of the Archivio di Stato, Record Office of Turin, an exhibition, named "Strumenti ritrovati" [1], was organized: it highlighted many examples of instruments of the past related to the different scientific academic disciplines taught in our University. One year later ASTUT was born.

The choice of the name was considered fundamental, it would have been "Archives" and not "Museum", an institution devoted to preserve, catalogue, study and bring out the instruments and the objects of science and technology that are under risk to disappear but with the consciousness that it would hardly ever become a real museum open to the public.

We organise temporary exhibitions about different themes using the available materials, paying a special attention to right setting and using originals photographs and when it is possible we make instruments work again and realize videos to help people understanding how they actually work.

We continue every day to collect instruments and other objects forsaken in the modern laboratory in order to take care of them as a "memory for the future". In a not too far future they will be important as they will be studied to understand all the steps of the history of science and technology.

We have more than 3,000 square meters of exhibition rooms and warehouses where we house thousands of specimens from the scientific and teaching history of the University since eighteenth century to yesterday (Figures 1 and 2).

In the second section we will discuss about professor Angelo Mosso and his studies and researches; in the section three we will explain the use of new transducers and the new instruments applied in different fields of the physiology. In the last section the evolution and the relevance of the studies of Angelo Mosso are highlighted. 




Figure 1. One of the exhibition rooms.

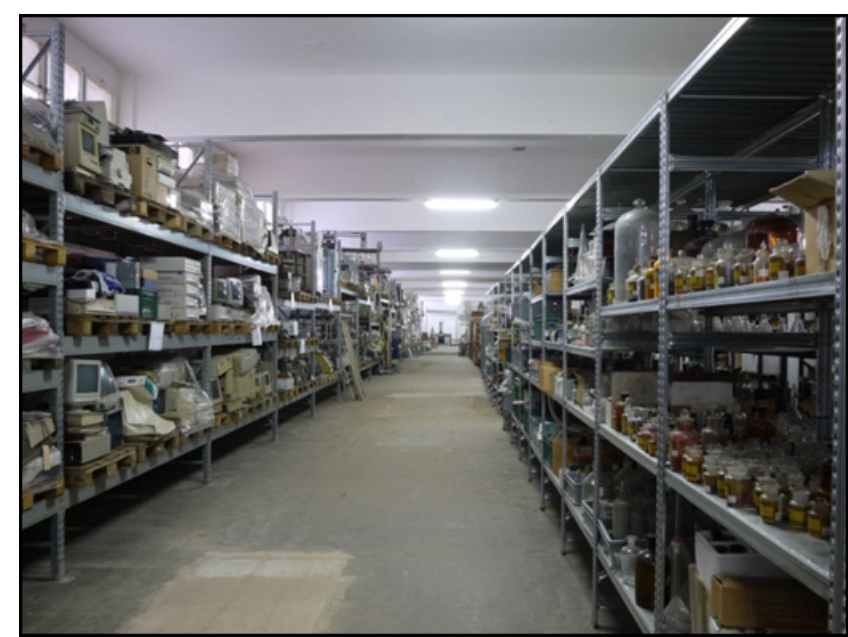

Figure 2. One of the warehouses .

\section{ANGELO MOSSO}

Angelo Mosso (Figure 3) was born in 1846, he studied medicine and succeeded Jacob Moleschott (1822-1893) as professor of Physiology in Turin. Moleschott was a materialistic philosopher rather than a physiologist and his researches were devoted especially to biochemistry. Mosso after the academic degree in 1870 moved to Florence and had the opportunity to attend the laboratory of Moritz Schiff (1823-1896) and then went to Leipzig, where he worked with Carl Ludwig (1816-1895). In Germany he learnt to use the kymograph (Figure 4), a new instrument invented by Ludwig to record biological phenomena. The kymograph consists of a drum that is covered by a smoked sheet of paper.

It rotates at a constant speed moved by a clockwork mechanism so that a mobile fine stick can draw a line that represents the variations in time of physiological parameters. This instrument had a revolutionary importance: for the first time it was possible to obtain a graphic record of biological events.

After his German period he spent some months in Paris, where he met Claude Bernard (1813-1878) and Jules Marey (1830-1904) and began to use the tympanum of Marey (Figure 5). The tympanum is made of a metal cylinder, closed by an elastic membrane on a side. Changes in pressure transmitted

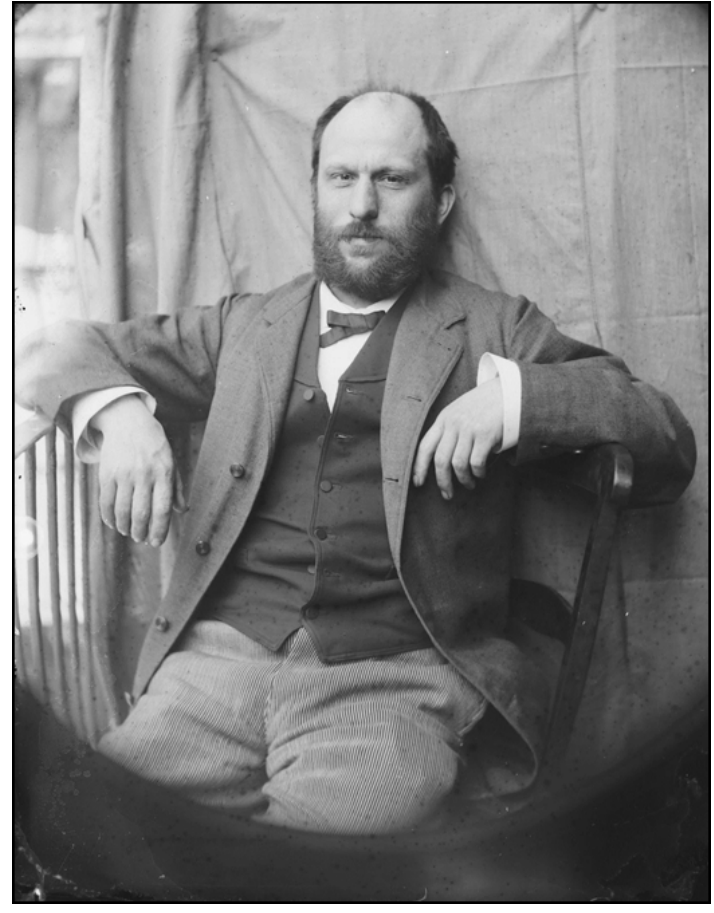

Figure 3. Angelo Mosso.

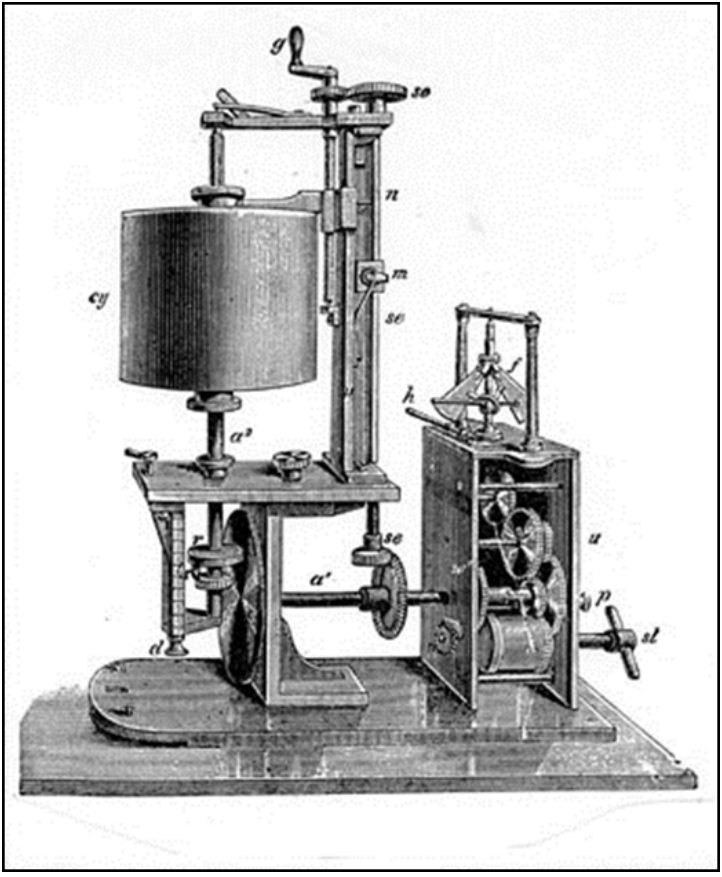

Figure 4. Kymograph.

to the tympanum via a pneumatic or hydraulic system acted on the membrane and caused the movement of a linked stick or a pen drawing on the kymograph drum.

These are the words used by Mosso about this technique: "Every heartbeat, every wheezing breath, tremor of the muscles, speed of blood circulation, speech, thought and perception can leave an indelible trace through the graphical method." [2].

When Mosso came back in Italy he could use both kymograph and tympanum in his experimental researches. The original and innovative ideas of the physiologist could 




Figure 5. Marey tympanum.

become actual instruments thanks to the quality of the work done by the technician Luigi Corino, who followed for many years Mosso.

We know that the ability in mechanical manufacture of this humble scientific craftsman was often important in order to obtain the best realization of the instruments and to improve their utilization and functionality. In our stores we have many instruments signed L. Corino and many others are present in different scientific instruments collections not only in Turin.

\section{NEW TRANSDUCERS}

The availability of a reliable graphic recorder induced Angelo Mosso to invent various transducers of physiologic events.

First of all there was the plethysmograph [3]: it was made of a glass cylinder into which the distal part of a limb could be introduced. From the cylinder full of water, the variations of volume of the limb were transferred with a hydraulic transmission to a glass pressure gauge with a mercury column which moved a pen on the paper of a kymograph. The recorded changes are caused by variations of local blood flow, that is influenced by emotional states and variations of other contemporary physiological activities.

The inertia of the recording system was too high and Mosso improved his instrument and built the hydrosphygmograph [4], based on mixed hydraulic and pneumatic transmission system (Figure 6).

With this tool the physiologist studied the movements of the brain in people with skull defects. He put a tympanum of Marey in contact with the head skin where the lack of bone allowed to perceive the movements of blood vessels through the meninx, and via a pneumatic system these volume variations were recorded so that it was possible to find relationships between mental activity and cerebral circulation.

Mosso invented also a sphygmomanometer [5]: it was a mercury manometer, with a pen on the meniscus surface. The patient had to put middle and ring fingers of both hands into rubber glove fingers placed in four metal tubes. The space between the walls of the tubes and the glove fingers was filled with water which transmitted the pressure oscillations of the fingers arteries to the manometer via a hydraulic system. In 1896, pediatrician Scipione Riva-Rocci (1863-1937) from Turin modified Mosso's instrument and obtained the arm cuff sphygmomanometer which is still used at present.

Mosso focused his attention on the distribution of blood in the entire human body. To this purpose, he built the bascule [6], an oscillating bed (Figure 7).

A patient resting on this bed, being exactly balanced on his

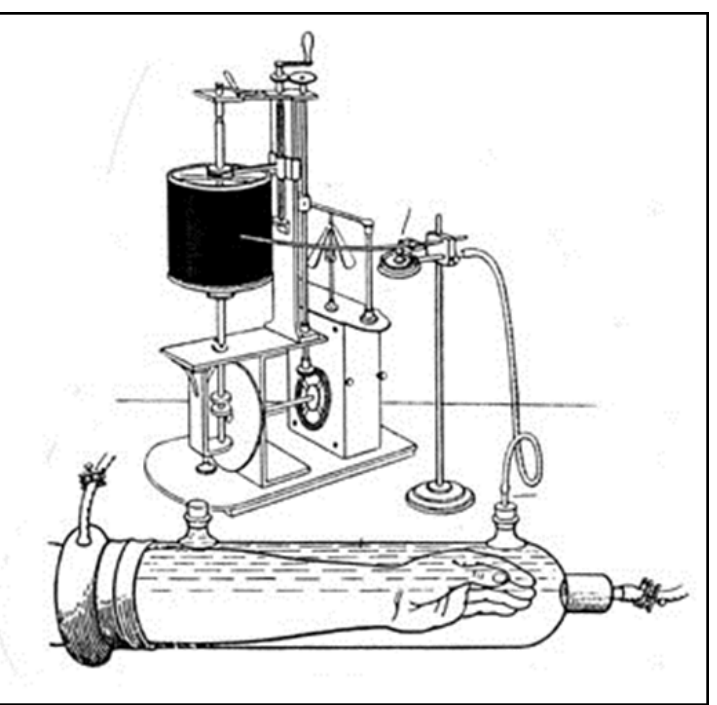

Figure 6. Hydrosphygmograph.

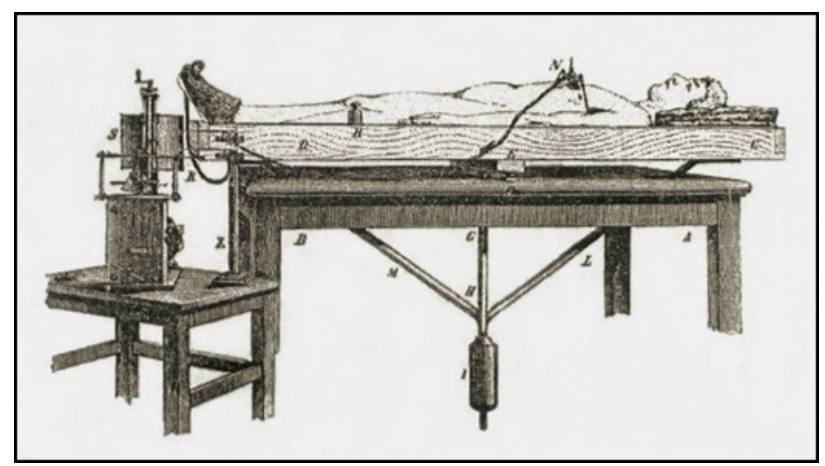

Figure 7. Bascule.

centre of gravity, slightly and continuously oscillated mainly in response to the respiratory movements, so that correlations between respiration and circulation could be identified through the simultaneous record of the blood flow in the foot, by means of a plethysmograph. Later on, Mosso tried to study the relationship between the distribution of the blood to the brain and different types of stimulation in the attempt to correlate neural activity and energy supply.

Mosso investigated also on muscle work and fatigue: for this purpose he created the ergograph [7] (Figure 8).

In this instrument an arm is held and locked in the right position while a string, with a weight of five, six kilos at the

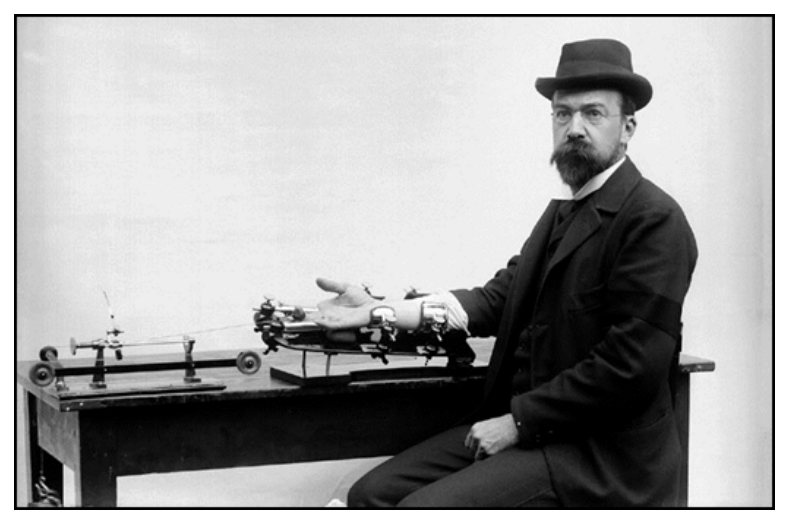

Figure 8. Ugolino Mosso, Angelo's brother, and the ergograph. 
end, is attached to the middle finger.

The contractions and releases of the finger, following the regular movement of a metronome, are recorded on blackened paper with a nib on a kymograph, in this case the signal transduction is mechanical and it is possible to draw the curve of the fatigue. Angelo Mosso recorded these graphs, ergograms, submitting many people to such experiments in different physical, psychological and environmental conditions.

As the researcher understood that there was a significant influence of the nervous component in the development of fatigue, the ergograph was modified and became the ponometer [8] (Figure 9).

In this instrument the lifted weigh could be automatically disconnected at the end of the contraction, reducing the mechanical work exerted by the muscle and so stressing the effect of the mental strain.

\section{CONCLUSIONS}

Angelo Mosso was a creative researcher, indeed he invented several instruments for the record of physiologic events, some of which were very sensitive as they were conceived for quite feeble events. The first problem was the technique for transferring the signal picked up by the sensor to the kymograph, and this was initially obtained with simple mechanical means, like in the ergograph. Hydraulic and pneumatic methods were adopted in other instruments, using glass tube manometers or the Marey tympanum. The weakness of the physiologic signals often needed amplification to draw a clearly visible graphic trace on the recording paper and this was obtained only applying a long and light stick, often made of bamboo wood, that operated as a third class lever and increased the original movement according to the length ratio of the two segments, the first

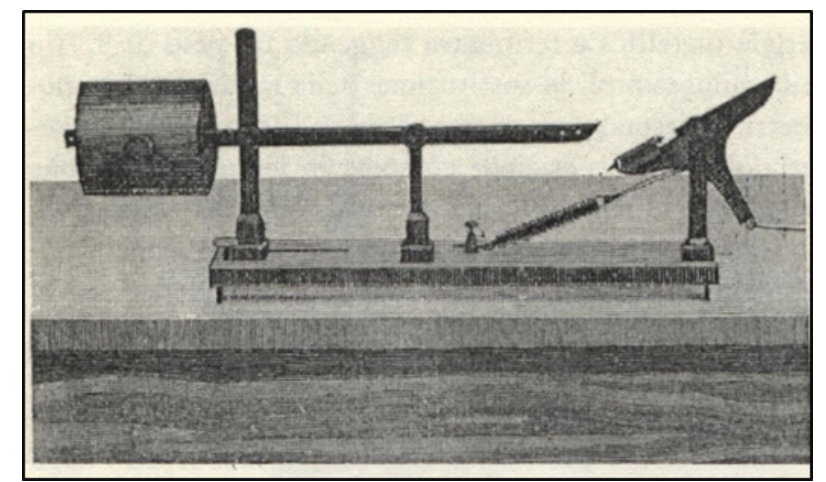

Figure 9. Ponometer. between fulcrum and effort (e.g. the Marey tympanum) and the second from the effort to the writing end. In these devices all mechanical variables, such as friction and viscosity, had to be taken into account as those factors could reduce the effectiveness of the system. For example, in the hydraulic transmission of the hydrosphygmograph the liquid was petroleum ether because of its low density [9].

Electronic amplification of electric signals by means of thermionic tubes was not yet available when Mosso was conducting his researches. Indeed, the only application of electricity he mentioned dealt with the writing of a time-base line on the paper of the kymograph that was needed for the measure of physiologic events duration. Electric contacts on the gears of a clockwork could activate an electromagnet, powered by Daniell cells, if a signal in the range of seconds was necessary. If there was the need for a higher frequency, the vibrations of a diapason could be picked up with a magnet attached to one of the prongs and surrounded by an electric wire coil. The induced current was sent to a Deprez's signal, an electromagnet that moved a marking shaft.

\section{REFERENCES}

[1] M. Galloni (ed.) "Strumenti ritrovati. Materiali della ricerca scientifica in Piemonte tra Settecento e Ottocento", Regione Piemonte, Torino, 1991.

[2] A. Mosso, "Carlo Ludwig", Nuova Antologia. Rivista di Scienza, Lettere ed Arti vol. 57, 1895, pp. 650-671.

[3] A. Mosso "Sopra un nuovo metodo per scrivere i movimenti dei vasi sanguigni nell'uomo"Atti della Reale Accademia delle Scienze di Torino, vol. IX, 1875, pp. 21-81.

[4] A. Mosso "Sulle variazioni locali del polso nell'antibraccio dell'uomo" Atti della Reale Accademia delle Scienze di Torino, vol. XIII, 1877, pp. 34-78.

[5] A. Mosso "Sphygmomanomètre pour mesurer la pression du sang chez l'homme", Archives Italiennes de Biologie, vol. XXIII, 1895, pp. 177-197.

[6] A. Mosso "Applicazione della bilancia allo studio della circolazione sanguigna dell'uomo" Atti della Reale Accademia dei Lincei - Memorie della Classe di Scienze Fisiche, Matematiche e Naturali, vol. XIX, 1884, pp. 534-535.

[7] A. Mosso "Le leggi della fatica studiate nei muscoli dell'uomo" Atti della Reale Accademia dei Lincei - Memorie della Classe di Scienze Fisiche, Matematiche e Naturali, vol. V, 1888, pp. 409426.

[8] A. Mosso "Le leggi della fatica studiate nei muscoli dell'uomo" Atti della Reale Accademia dei Lincei - Memorie della Classe di Scienze Fisiche, Matematiche e Naturali, vol. V, 1888, pp. 419421.

[9] A. Mosso "Applicazione della bilancia allo studio della circolazione sanguigna dell'uomo" Atti della Reale Accademia dei Lincei - Memorie della Classe di Scienze Fisiche, Matematiche e Naturali, vol. XIX, 1884, pp. 534-535. 